\title{
Perancangan dan Implementasi Konfigurasi Wifi Router dan Jaringan Wireless dengan Rb951ui-2nd
}

\author{
Basorudin*, Erni Rouza, Budi Yanto, Satria Riki Mustafa \\ Fakultas Ilmu Komputer, Prodi Teknik Informatika, Universitas Pasir Pengaraian, Pasir Pengaraian, Indonesia \\ Email: 1,"basorudin09@gmail.com, ${ }^{2}$ ernirouzait@gmail.com, ${ }^{3}$ budiyantost@gmail.com, ${ }^{3}$ satriarikimustafa@gmail.com \\ Email Penulis Korespondensi: basorudin09@gmail.com \\ Submitted: 15/12/2021; Accepted: 27/12/2021; Published: 31/12/2021
}

\begin{abstract}
Abstrak-Jaringan Komputer berkembang dengan sangat pesat, baik di instansi-instansi komersil, dunia akademik, bahkan rumah-rumah penduduk yang membutuhkan akses internet. Internet diakses oleh banyak orang tanpa terkecuali hacker dan cracker.[1] Dalam konfigurasi nanti output yang dihasilkan adalah berupa pembuatan homepage untuk Login user hotspot, firewall yaitu blocking site, RADIUS, Blocking akses internet pada waktu yang telah ditentukan dan pembuatan SSID. Konfigurasi ini sangat diperlukan saat kita akses internet terutama untuk sekolah, karena dengan dibangunnya konfigurasi ini maka siswa dapat kita batasi penggunaan jam akses internetnya, dan siswa tidak diizinkan akses situs tertentu di jam belajar, misalnya situs youtube, facebook dan lain-lain, dengan konfigurasi wifi router dan jaringan wireless guru juga dapat membatasi siapa saja yang bisa akses internet di hari tertentu dan jam tertentu, khusunya di SMK N 1 Pendalian 4 koto. Dari hasil uji coba yang telah dilakukan menunjukkan keberhasilan, mulai dari uji koneksi internet, baik ping ke router maupun ping ke google, dan juga saat guru dan siswa akses internet melalui login hotspot dengan voucher yang telah disediakan juga berhasil, kemudian hasil pengujian untuk pembatasan waktu akses internet juga telah berhasil, melakukan blocking situs juga telah berhasil dilakukan. Jadi dapat disimpulkan bahwa penelitian tentang konfigurasi wifi router dan internet di SMK Negeri 1 Pendalian IV Koto telah berhasil.
\end{abstract}

Kata Kunci: Jaringan Komputer; Hotspot; Firewall; Wifi Router

Abstract-Computer networks are growing very rapidly, both in commercial institutions, the academic world, and even people's homes that need internet access. The internet is accessed by many people without exception of hackers and crackers.[1] In the configuration, the output generated is in the form of making a homepage for hotspot user logins, firewalls, namely blocking sites, RADIUS, Blocking internet access at a predetermined time and making SSID. This configuration is very necessary when we access the internet, especially for schools, because with the construction of this configuration, we can limit the use of internet access hours, and students are not allowed to access certain sites during study hours, for example YouTube, Facebook and others, with this configuration Wifi routers and teachers' wireless networks can also limit who can access the internet on certain days and certain hours, especially at SMK N 1 Pendalian 4 Koto. From the results of the trials that have been carried out, it shows success, starting from the internet connection test, both ping to the router and pinging to google, and also when teachers and students access the internet via hotspot login with the voucher that has been provided also successful, then the test results for time restrictions internet access has also been successful, site blocking has also been successfully carried out. So it can be concluded that the research on wifi router and internet configuration at SMK Negeri 1 Pendalian IV Koto has been successful.

Keywords: Computer Network; Hotspot; Firewall; Wifi Router

\section{PENDAHULUAN}

Jaringan Komputer berkembang dengan sangat pesat, baik di instansi-instansi komersil, dunia akademik, bahkan rumah-rumah penduduk yang membutuhkan akses internet. Internet diakses oleh banyak orang tanpa terkecuali hacker dan cracker [1]. Saat ini telah banyak orang yang menggunakan media internet sebagai kebutuhan primer dalam menjalani pekerjaan masing-masing orang. Sehingga semakin berkembang pula aplikasi-aplikasi, mediamedia, dan banyak lagi cara mudah dalam penggunaan akses internet. Salah satu cara aman dan memudahkan penggunaan internet yaitu dengan dilakukan konfigurasi wifi router dan jaringan wireless terlebih dahulu. Sebuah router mentransmisikan informasi dari satu jaringan ke jaringan yang lain melalui sebuah jaringan internet menuju tujuannya melalui sebuah proses yang disebut sebagai routing. Router hampir sama dengan Bridge namun memiliki kelebihan, router akan mencari jalur yang terbaik untuk mengirimkan sebuah pesan yang berdasakan atas alamat tujuan dan alamat asal [2]. Sedangkan Wireless LAN (WLAN) atau Wireless Fidelity (Wi-Fi), yaitu teknologi yang digunakan untuk mentransmisikan data yang berjalan pada jaringan komputer lokal tanpa penggunaan kabel dengan menggunakan infrastruktur dan media transmisi yang baru, dalam hal ini adalah gelombang radio. Agar berbagai macam produk Wireless LAN yang berasal dari vendor yang berlainan dapat saling bekerja sama/kompatibel pada jaringan[3]. Dalam artikel ilmiah ini akan dibuatkan bagimana mengkonfigurasi wifi router dan jaringan wireless pada SMK Negeri 1 Pendalian 4 Koto dengan perangkat TP Links dan RB951Ui-2ND serta software bawaan mikrotik yaitu Winbox.

Penelitian terdahulu yang diangkat oleh Ilham Eka Putra, (2013) dengan judul Perancangan Jaringan Hotspot Berbasis Mikrotik Router Os 3.3.0, Berdasarkan hasil desain jaringan hotspot menggunakan Mikrotik Router OS 3.3.0 dapat diambil beberapa kesimpulan bahwa Mikrotik Router OS 3.3.0 dapat mengunakan sebuah sistem billing yang dapat mengatur dan membatasi client-client dalam mengunakan akses internet dimana semua pihak dalam hal ini klien dan manajemen tidak ada yang dirugikan, dengan kata lain saling menuntungkan [4].

Penelitian lain yang diangkat oleh Muhammad Ibrahim Hasan, (2016) dengan judul Analisa Dan Pengembangan Jaringan Wireless Berbasis Mikrotik Router Os V.5.20 Di Sekolah Dasar Negeri 24 Palu. Dalam 
artikel penelitian ini menunjukkan bahwa pengembangan jaringan wireless menggunakan Mikrotik Router OS v.5.20 dengan memanfaatkan Personal Computer (PC) sebagai router untuk mengolah dan mengkonfigurasikan management bandwidth, web filtering, dan user management dapat mengamankan dan mengoptimalkan pemakaian jaringan wireless pada SDN 24 Palu [5].

Dalam penelitian ini ada perbedaan yang akan dihasilkan dari penelitian sebelumnya dalam konfigurasi nanti output yang dihasilkan adalah berupa pembuatan homepage untuk Login user hotspot, firewall yaitu blocking site, RADIUS, Blocking akses internet pada waktu yang telah ditentukan dan pembuatan SSID. Konfigurasi ini sangat diperlukan saat kita akses internet terutama untuk sekolah, tujuan dari dibangunnya sistem ini adalah agar siswa disekolah dapat kita batasi penggunaan jam akses internetnya, dan siswa tidak diizinkan akses situs tertentu di jam belajar, misalnya situs youtube, facebook dan lain-lain, dengan konfigurasi wifi router dan jaringan wireless guru juga dapat membatasi siapa saja yang bisa akses internet di hari tertentu dan jam tertentu. Kenapa judul artikel ini di angkat di SMK Negeri 1 Pendalian 4 Koto karena disekolah tersebut internetnya belum dikonfiguras sama sekali artinya masih sangat terbuka siapa saja bisa mengakses.

\section{METODOLOGI PENELITIAN}

Pada tahapan ini akan dijelaskan metode yang dilakukan peneliti dalam merancang dan mengimpelentasikan Konfigurasi Wifi Router dan Jaringan Wireless Dengan Rb951ui-2nd. Penelitian ini dilakukan dengan melaksanakan tahapan demi tahapan yang saling berhubungan. Tahapan-tahapan tersebut digambarkan dengan kerangka penelitian pada gambar 1.

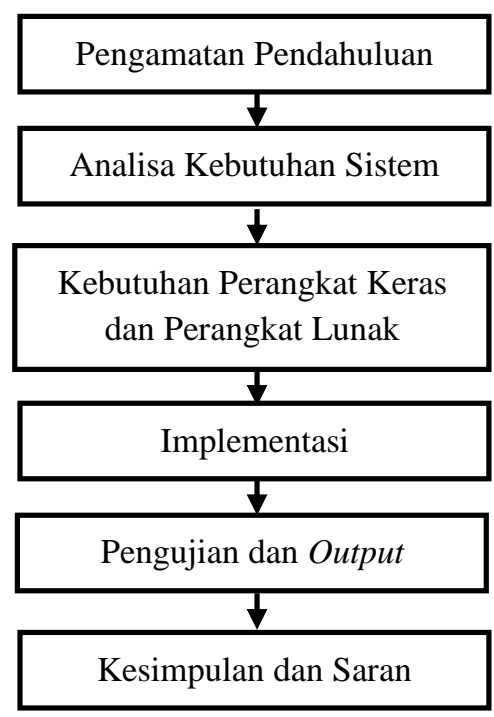

Gambar 1. Kerangka Penelitian

\subsection{Pengamatan Pendahuluan}

Pengamatan pendahuluan merupakan tahapan awal yang dilakukan dalam penelitian ini, bertujuan untuk mengamati penelitian sebelumnya, berkaitan dengan konfigurasi jaringan wireless dan hotspot dengan mikrotik router yang dijadikan sebagai penelitian studi pustaka dalam penelitian ini. Hasil dari pengamatan pendahuluan ini berupa penelitian sebelumnya yang melakukan penelitian terkait dengan judul atau kasus yang mendekati. Pada penelitian ini dilakukan di SMK Negeri 1 Pendalian IV Koto yaitu dengan judul Perancangan dan Implementasi Konfigurasi Wifi Router dan Jaringan Wireless Dengan Rb951ui-2nd.

\subsection{Analisis Kebutuhan Sistem}

\subsubsection{Sistem Usulan}

Internet adalah media yang sangat efektif dalam berkomunikasi dibandingkan dengan media yang lain, sehingga internet menjadi kebutuhan primer di era globalisasi saat ini [6]. Dalam penelitian ini internet berfungsi untuk menyuplai akses jaringan internet utama, sedangkan aplikasi WinBox ini sebagai alat untuk konfigurasi Wifi Router dan Jaringan Wireless di SMK Negeri 1 Pendalian IV Koto menggunakan Router Board 951Ui-2ND. TP Links sendiri berfungsi sebagai penyebar jaringan internet di dalam gedung sekolah untuk para guru dan siswa, yang mana guru dan siswa dapat akses internet sesuai dengan hasil konfigurasi pada WinBox di laptop server, seperti pembatasan jam akses internet, pembatasan akses youtube, facebook saat proses belajar berlangsung, harus login terlebih dahulu jika mau akses internet, pembatasan bandwitdh dal lain-lain. 


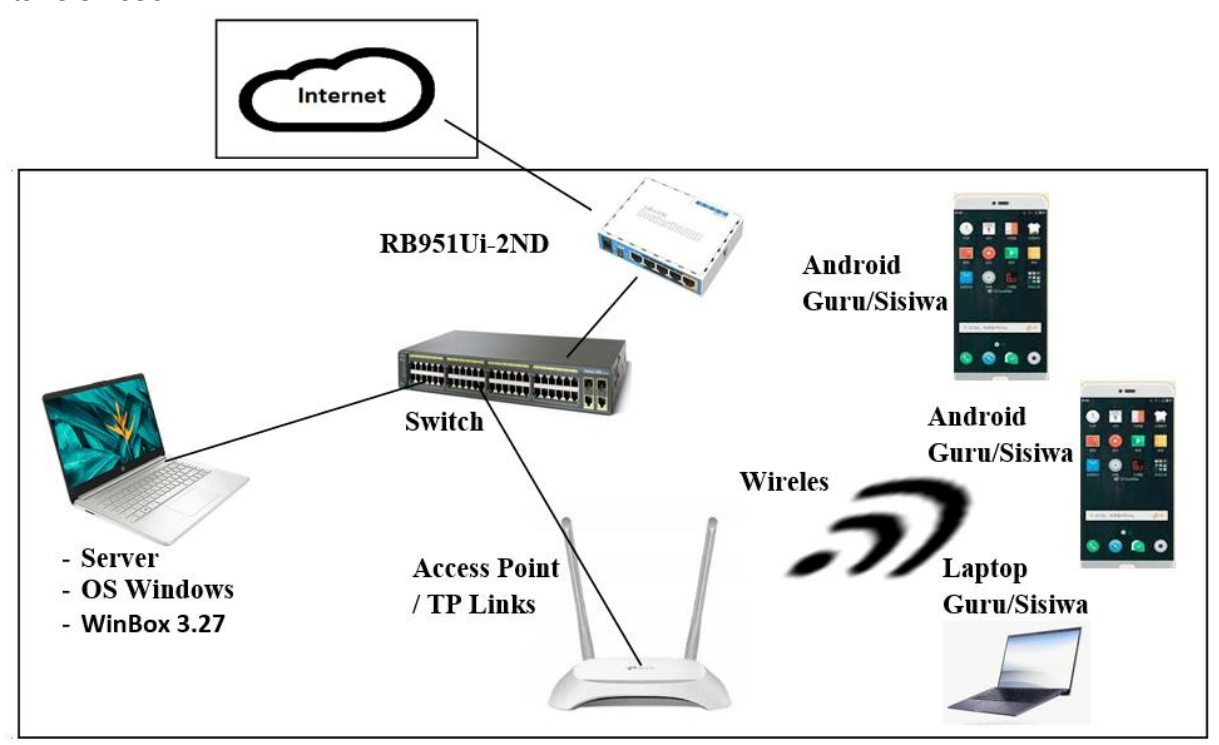

Gambar 2 Topologi Usulan

Berikut ini penjelasan dari gambar 3 alur kerja sistem dibawah ini:

1. Internet berfungsi untuk menyuplai akses jaringan internet utama.

2. Sedangkan aplikasi WinBox ini sebagai alat untuk konfigurasi Wifi Router dan Jaringan Wireless di SMK Negeri 1 Pendalian IV Koto menggunakan Router Board 951Ui-2ND.

3. Guru dan Siswa dapat terhubung internet menggunakan login page melalui TP Links hasil dari konfigurasi di WinBox.

4. Hasil konfigurasi pada WinBox di laptop server yaitu, seperti pembatasan jam akses internet, pembatasan akses youtube, facebook saat proses belajar berlangsung, harus login terlebih dahulu jika mau akses internet, pembatasan bandwitdh dal lain-lain.

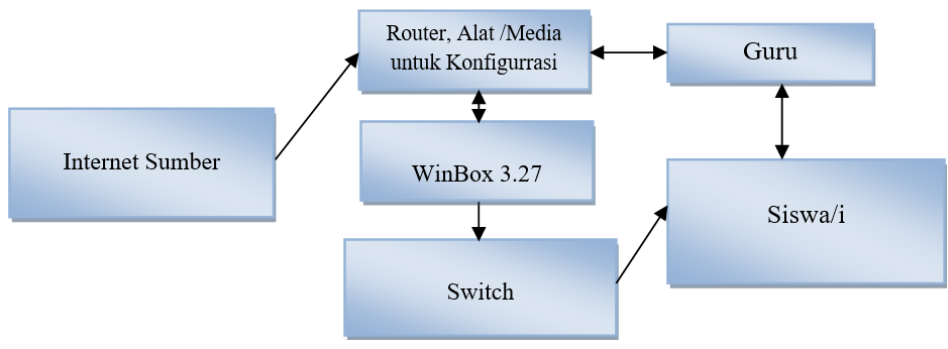

Gambar 3. Alur Kerja Sistem

\subsubsection{Rencana Pengujian}

Rencana pengujian dengan menggunakan simulasi yang memakai beberapa client seperti guru dan siswa sebagai parameter pengukuran terhadap sample yang diambil pada sekolah SMK Negeri 1 Pendalian IV Koto, dan beberapa parameter keberhasilan pada saat simulasi pengujian adalah sebagai berikut :

1. Melakukan Pengujian dari PC Client yang terhubung kabel :
a. Pengujian IP DHCP Client
b. Pengujian Koneksi internet
c. Pengujian Blocking ping dari client

2. Melakukan Pengujian dari smartphone yang terhubung wireless:
a. Pengujian Login user ke hotspot
b. Pengujian Blocking Site, misalnya www.youtube.com, fb, dan lain-lain
c. Pengujian Blocking File, misalnya .mp3, .mkv
d. Pengujian Blocking akses internet pada waktu yang telah ditentukan, misalnya siswa bisa akses internet dari pukul 12.00 sampai pukul 16.00 Wib.

\subsubsection{Kebutuhan Perangkat Keras dan Perangkat Lunak}

Perangkat keras dan perangkat lunak yang dibutuhkan untuk sistem adalah sebagai berikut :

1. Perangkat Keras

a. 1 buah Personal Komputer atau Laptop sebagai server

b. 2 buah HP Smartphone dan 1 unit laptop, sebagai client yang nantinya akan dipakai pada tahap pengujian. 
ISSN 2685-3310 (media online)

DOI 10.47065/bits.v3i3.1036
c. Access Point / TP Links
d. RB951Ui-2ND
e. Switch
f. Kabel UTP Straight

2. Perangkat Lunak
a. OS berbasis Windows
b. WinBox
c. Munin
d. Mikhmon

\section{HASIL DAN PEMBAHASAN}

Konfigurasi Wifi Router dan Jaringan Wireless dengan RB951Ui-2ND akan dijelaskan pada sub bab berikut yang terdapat juga langkah-langkah dalam pembangunan sistemnya serta hasil akhir dari pengujian.

\subsection{Implementasi}

\subsubsection{Pembangunan Server}

Berikut adalah tahapan-tahapan konfigurasi dari komputer server menggunakan WinBox.

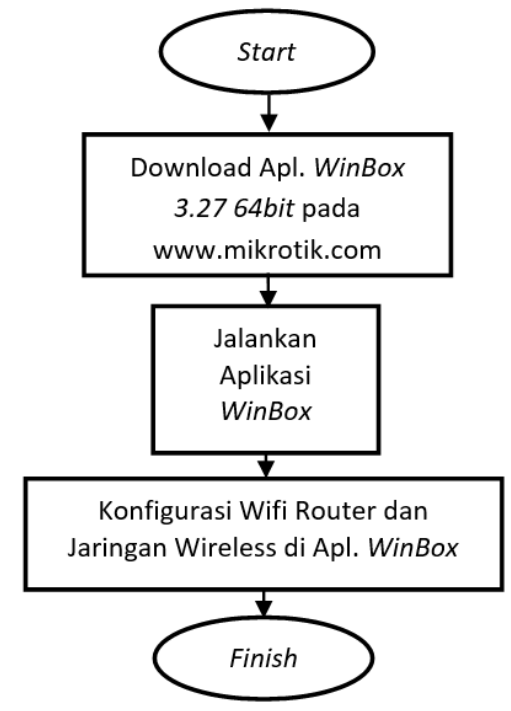

Gambar 4. Konfigurasi Wifi Router dan Jaringan Wireless

\subsubsection{Tahapan Konfigurasi}

Proses membuat nama atau identity

a. Membuat nama atau Identity

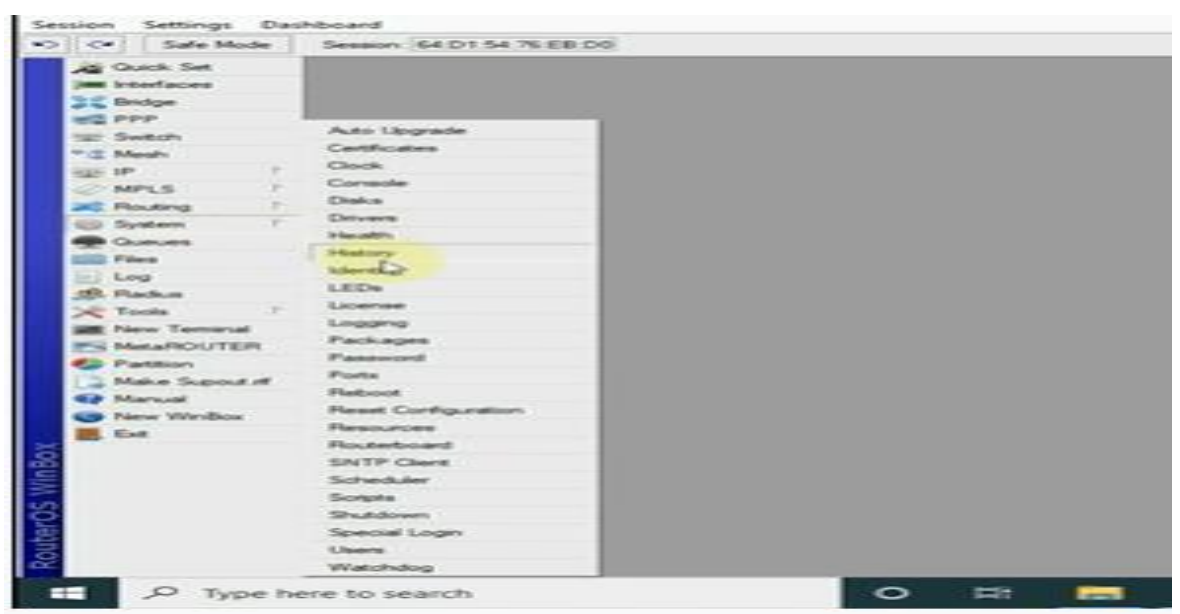

Gambar 5. Membuat Identity 
Building of Informatics, Technology and Science (BITS)

Volume 3, No 3, December 2021, Page 186-193

ISSN 2684-8910 (media cetak)

ISSN 2685-3310 (media online)

DOI 10.47065/bits.v3i3.1036

b. Pengujian Koneksi Internet

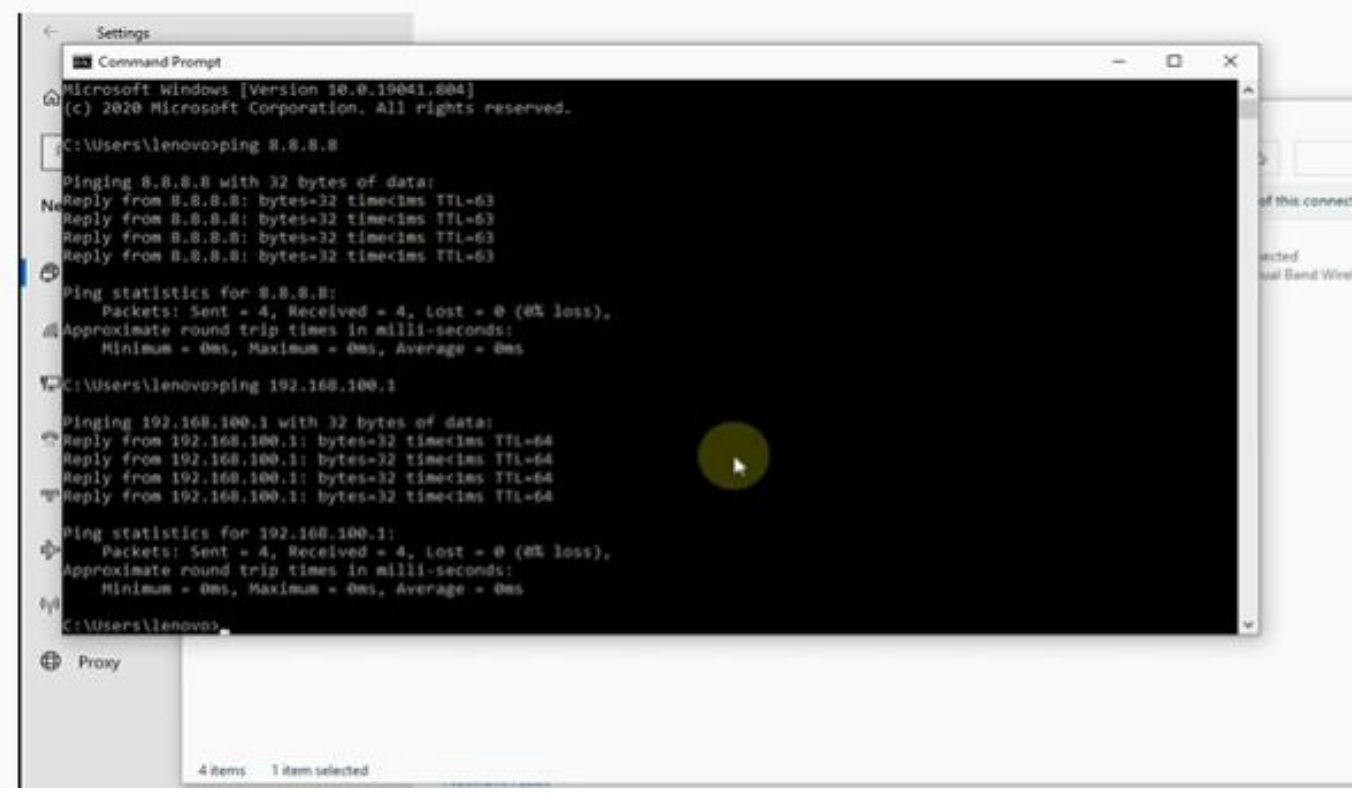

Gambar 6. Pengujian Koneksi Internet

c. Tampilan voucher untuk login Hotspot

\begin{tabular}{|c|c|c|c|c|}
\hline MIKHMON ${ }_{\text {Kemangi 41 }}{ }^{[1]}$ & MIKHMON ${ }_{\text {Kemangi 41 }}^{[2]}$ & MIKHMON Kemangi 41 & MIKHMON Kemangi 41 & MIKHMON Ke \\
\hline $\begin{array}{l}\text { Kode Voucher } \\
\text { qvwd } 9640\end{array}$ & $\begin{array}{l}\text { Kode Voucher } \\
\text { yyxr3582 }\end{array}$ & $\begin{array}{c}\text { Kode Voucher } \\
\text { arih9464 }\end{array}$ & $\begin{array}{l}\text { Kode voucher } \\
\text { ndpu } 4608\end{array}$ & $\begin{array}{l}\text { Kode Vo } \\
\text { hflz6e }\end{array}$ \\
\hline $\begin{array}{c}\text { 2d Rp5,000 } \\
\text { Login: http://k41-net }\end{array}$ & $\begin{array}{c}\text { 2d Rp5,000 } \\
\text { Login: http::/k41.net }\end{array}$ & $\begin{array}{c}\text { 2d Rp5,000 } \\
\text { Login: http:/ik41-net }\end{array}$ & $\begin{array}{c}\text { 2d Rp5,000 } \\
\text { Login: http://k41.net }\end{array}$ & $\begin{aligned} \text { 2d Rpt } \\
\text { Login: http: }\end{aligned}$ \\
\hline MIKHMON ${ }_{\text {Kemangi 41 }}^{[7]}$ & MIKHMON ${ }_{\text {Kemangi 41 }}{ }^{[8]}$ & MIKHMON Kemangi 41 $^{[9]}$ & MIKHMON ${ }_{\text {Kemangi 41 }}{ }^{[10]}$ & MIKHMON Ke \\
\hline \begin{tabular}{|c|} 
Kode voucher \\
fiyk9680 \\
\end{tabular} & \begin{tabular}{|c|} 
Kode Voucher \\
base 1635 \\
\end{tabular} & $\begin{array}{l}\text { Kode Voucher } \\
\text { dmwc1721 } \\
\end{array}$ & \begin{tabular}{|c|} 
Kode voucher \\
fzvl2050 \\
\end{tabular} & $\begin{array}{l}\text { Koce Vo } \\
\text { ckmx6 } \\
\end{array}$ \\
\hline $\begin{array}{c}\text { 2d Rp5,000 } \\
\text { Login: http://k41.net }\end{array}$ & $\begin{array}{c}\text { 2d Rp5,000 } \\
\text { Login: http:I/k41.net }\end{array}$ & $\begin{array}{c}\text { 2d Rp5,000 } \\
\text { Login: http:ink41.net }\end{array}$ & $\begin{array}{c}\text { 2d Rp5,000 } \\
\text { Login: httpi/k41.net }\end{array}$ & $\begin{array}{r}\text { 2d Rpt } \\
\text { Login: http: }\end{array}$ \\
\hline MIKHMON ${ }_{\text {Kemangi 41 }}^{\text {[13] }}$ & MIKHMON ${ }_{\text {Kemangi 41 }}{ }^{[14]}$ & MIKHMON ${ }_{\text {Kemangi 41 }}{ }^{[15]}$ & MIKHMON ${ }_{\text {Kemangi 41 }}{ }^{[16]}$ & MIKHMON Ke \\
\hline $\begin{array}{l}\text { Kode Voucher } \\
\text { apjs8263 }\end{array}$ & \begin{tabular}{|l|} 
Kode Voucher \\
xago9513 \\
\end{tabular} & \begin{tabular}{|c|} 
Kode Voucher \\
ajeu3800 \\
\end{tabular} & \begin{tabular}{|l|} 
Kode Voucher \\
bpmr1213 \\
\end{tabular} & $\begin{array}{l}\text { Kode Vo } \\
\text { elyp } 3\end{array}$ \\
\hline 2d Rp5,000 & 2d Rp5,000 & 2d Rp5,000 & 2d Rp5,000 & 2d Rpt \\
\hline
\end{tabular}

Gambar 7. Tampilan Voucher

d. Membatasi user saat akses internet

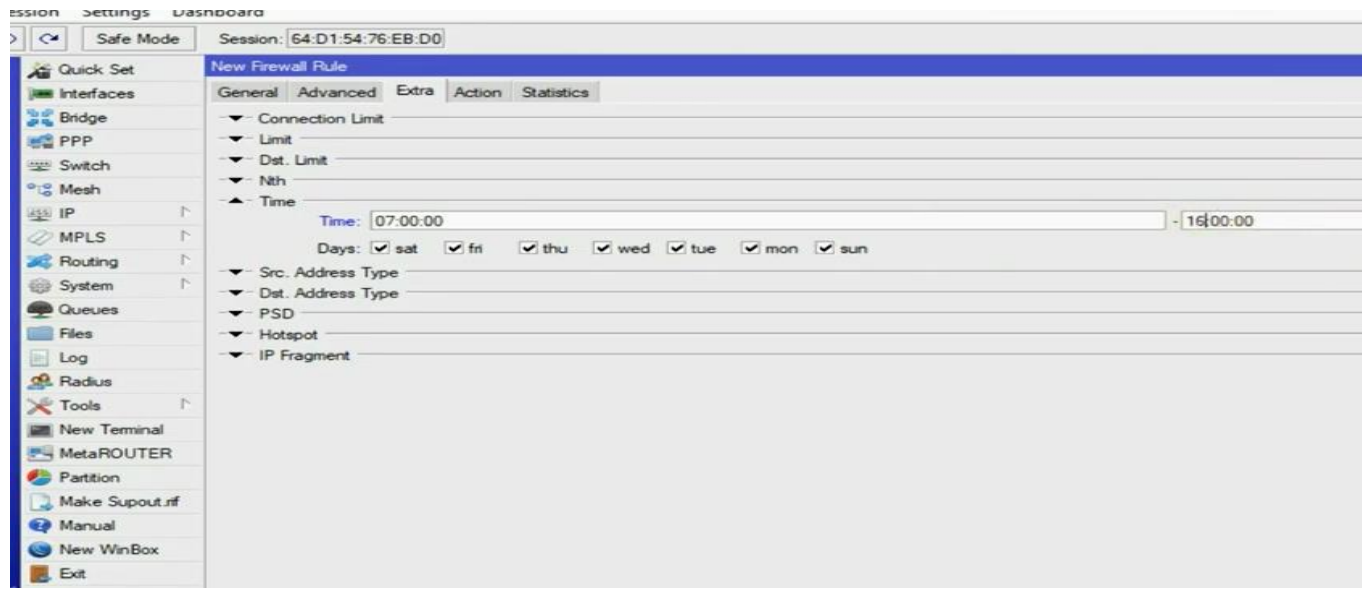

Gambar 8. Membatasi User Akses Internet

\subsection{Pengujian dan Output}

\subsubsection{Pengujian ke Smartphone Siswa dan Guru}

Pengujian ini dilakukan untuk menguji apakah konfigurasi Wifi Router dan Jaringan Wireless yang telah dikonfigurasi sudah dapat berjalan atau belum khusunya di SMK Negeri 1 Pendalian IV Koto. 
Building of Informatics, Technology and Science (BITS)

Volume 3, No 3, December 2021, Page 186-193

ISSN 2684-8910 (media cetak)

ISSN 2685-3310 (media online)

DOI 10.47065/bits.v3i3.1036

a. Pengujian Koneksi Internet

Pengujian ini digunakan untuk melihat apakah semua internet telah terkoneksi baik dari router ke internet maupun ke komputer clientnya.

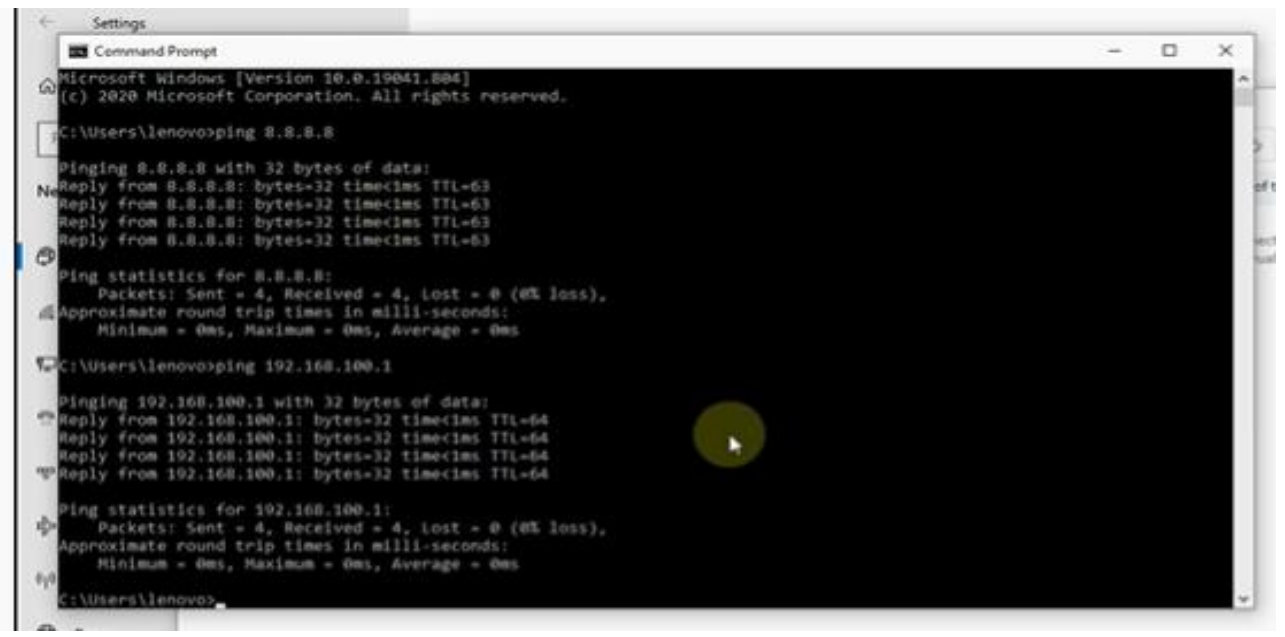

Gambar 9. Pengujian Koneksi Internet

\section{b. Pengujian ke Smartphone Siswa dan Guru}

Pengujian ke smartphone Siswa dan Guru bertujuan untuk melihat apakah smartphone sudah dapat mengakses internet dengan login terlebih dahulu dan apakah siswa dan guru sudah ada pembatasan waktu dalam penggunan akses internet.

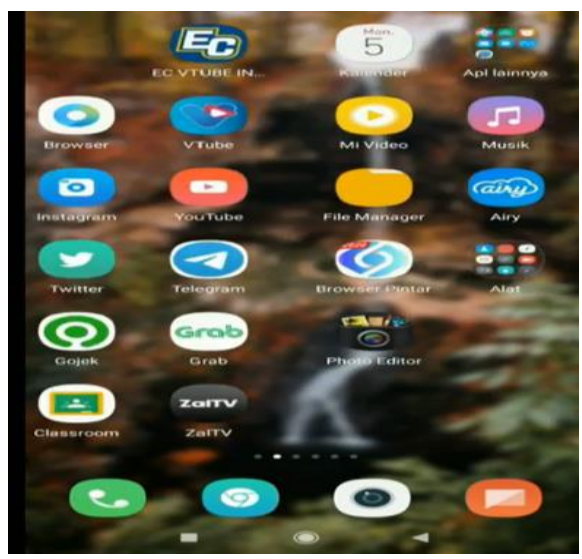

c. Masuk ke Setelan Wifi

Gambar 10. Pengujian ke smartphone siswa dan guru

Siswa dan Guru harus masuk kesetelan Wifi terlebih dahulu untuk dapat mengakses internet sekolah dan mencari wifi sekolah yang telah dikonfigurasi

\section{d. Masuk melalui login hotspot}

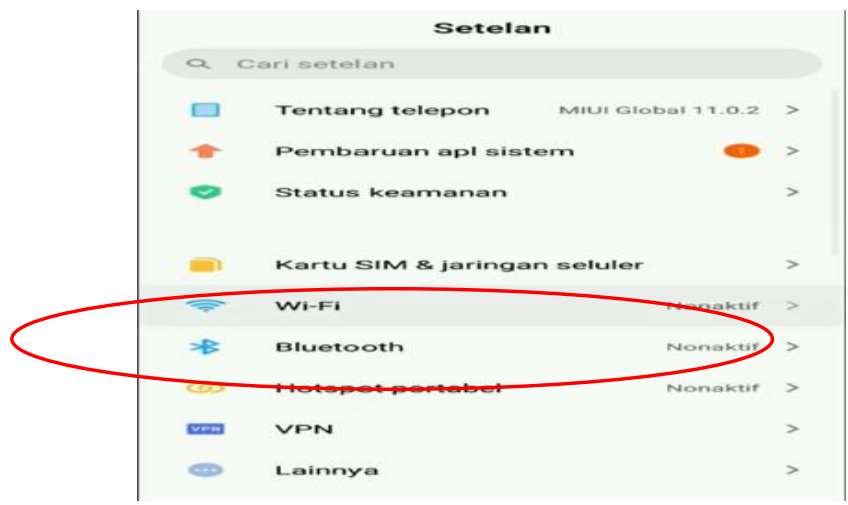

Gambar 11. Setelan Wifi

Siswa dan guru harus terlebih dahulu login untuk akses internet sekolah, jika semua guru dan siswa login terlebih dahulu saat akses internet berarti konfigurasi sukses/berhasil. 


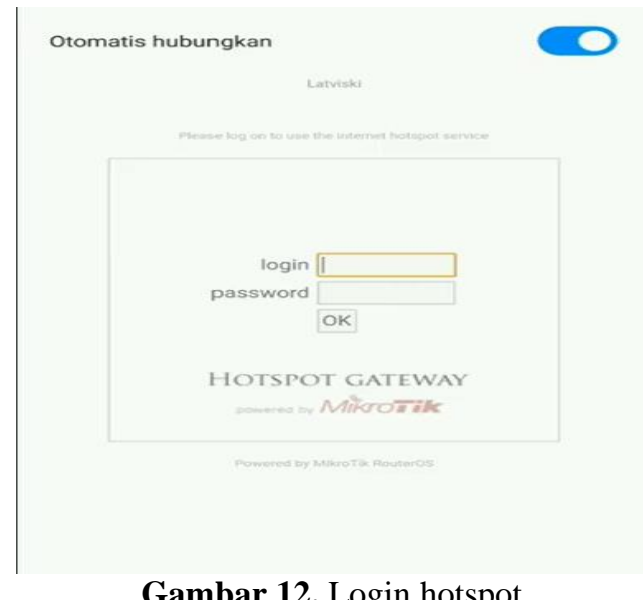

\section{e. Berhasil masuk ke google}

Gambar 12. Login hotspot

Berikut ini tampilan Siswa dan guru berhasil akses internet sekolah

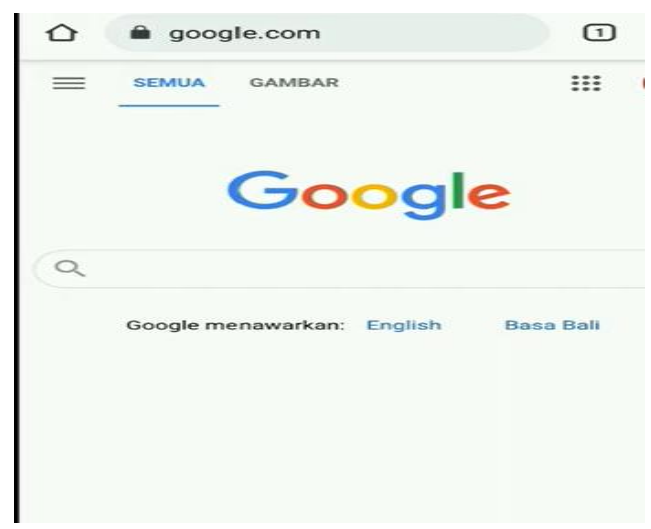

\section{f. Blok site detik.com}

Gambar 13. Berhasil Masuk ke Google

Konfigurasi berhasil karena ada beberapa website yang sudah tidak dapat di buka saat jam belajar, seperti facebook, youtube dan detik.com berikut contoh tampilannya :

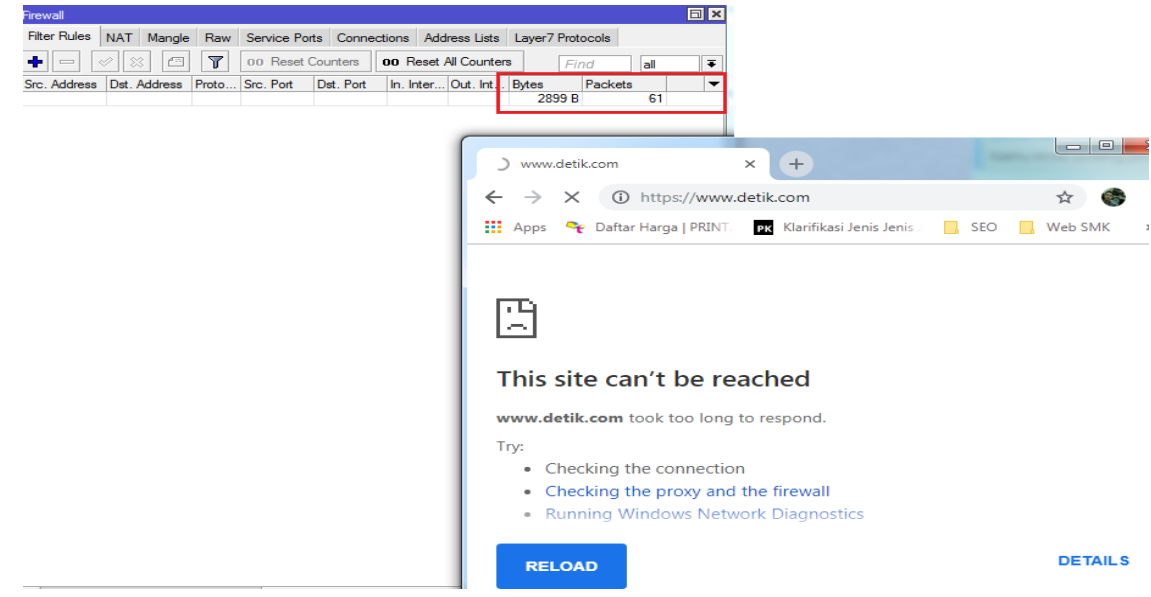

Gambar 14. Blok site detik.com

Berikut pada tabel 1 merupakan hasil uji akses ke server 1

Tabel 1. Hasil Uji Akses Ke Server 1

\begin{tabular}{|c|c|c|c|}
\hline Bagian Pengujian & Pengujian & Gagal & Berhasil \\
\hline \multirow{4}{*}{ Uji Koneksi } & Ping ke Router & & $\sqrt{ }$ \\
\hline & Ping ke Internet & & $\sqrt{ }$ \\
\hline & Akses DHCP & & $\sqrt{ }$ \\
\hline & Login Hotspot dgn Voucher & & $\sqrt{ }$ \\
\hline Login Hotspot & MP3 & & $\sqrt{ }$ \\
\hline
\end{tabular}




\begin{tabular}{clcc}
\hline \multicolumn{1}{c}{ Bagian Pengujian } & \multicolumn{1}{c}{ Pengujian } & Gagal & Berhasil \\
\hline & Facebook.com & & $\sqrt{ }$ \\
& detik.com & $\sqrt{ }$ \\
Blok situs & Youtube.com & $\sqrt{ }$ \\
\hline
\end{tabular}

\subsubsection{Hasil Tampilan Mikhmon}

Berikut ini adalah tampilan grafik bandwith dan lain-lain dari hasil uji coba

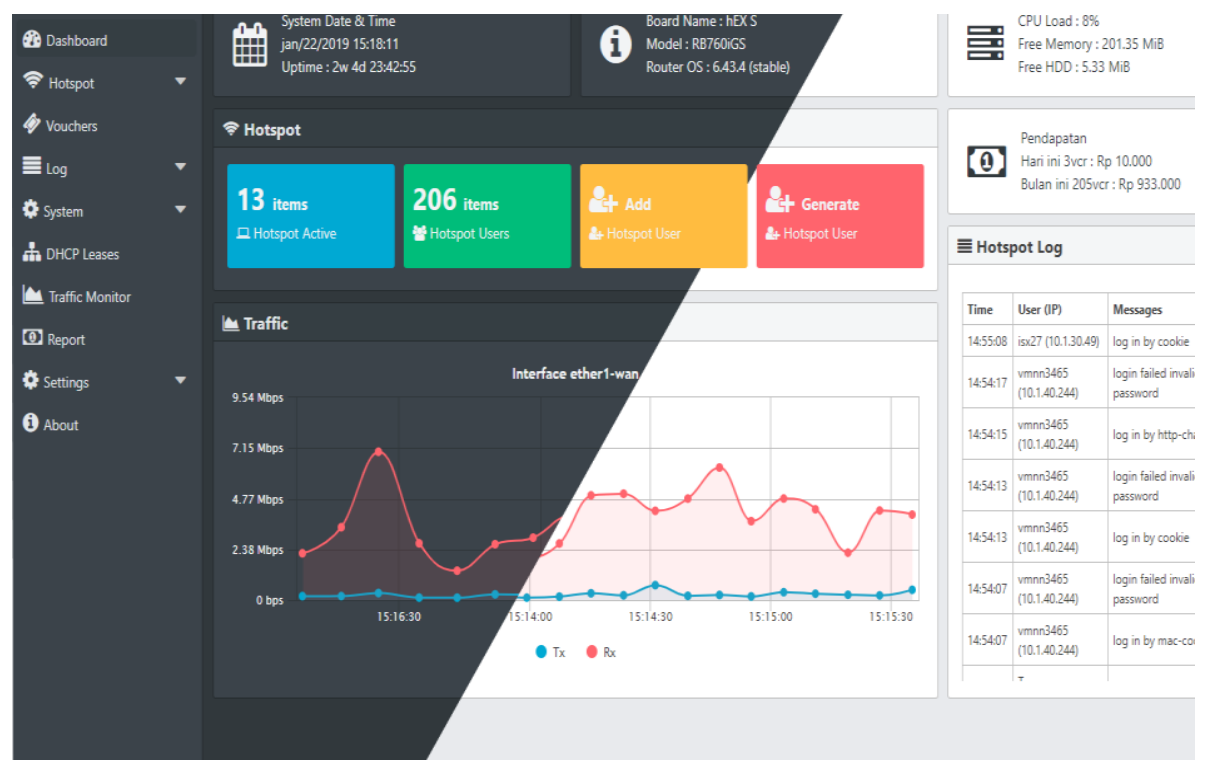

Gambar 15. Tampilan grafik bandwith

Dari hasil uji coba yang telah dilakukan menunjukkan keberhasilan, mulai dari uji koneksi internet, baik ping ke router maupun ping ke google, dan juga saat guru dan siswa akses internet melalui login hotspot dengan voucher yang telah disediakan juga berhasil, kemudian hasil pengujian untuk pembatasan waktu akses internet juga telah berhasil, melakukan blocking situs juga telah berhasil dilakukan. Jadi dapat disimpulkan bahwa penelitian tentang konfigurasi wifi router dan internet di SMK Negeri 1 Pendalian IV Koto telah berhasil.

\section{KESIMPULAN}

Berdasarkan hasil Konfigurasi Wifi Router dan Jaringan Wireless dengan RB951Ui-2ND pada SMK Negeri 1 Pendalian IV Koto, maka dapat disimpulkan bahwa Konfigurasi wifi router telah berhasil dan dapat dilihat saat pengujian dilakukan serta Pembuatan hotspot untuk login internet bagi guru dan siswa juga telah berhasil dan dapat memudahkan setelah dilakukan wawancara terhadap user, hasilnya sangat memuaskan dan sangat membantu masalah jaringan yang terjadi di SMK N 1 Pendalian IV Koto selama ini. Selanjutnya berdasarkan hasil uji coba Bloking situs juga telah berhasil dilakukan di saat-saat jam tertentu. Saran untuk pengembangan penelitian selanjutnya maka di sini penulis menyarankan agar Menambahkan atau menerapkan metode lain untuk judul tentang mikrotik ini kemudian Menggunakan aplikasi lain untuk pembuatan voucher login hotspot serta Menambahkan bloking situsnya jika di butuhkan oleh user.

\section{REFERENCES}

[1] Abdul Fadlil, At All. 2017, Pengembangan Sistem Pengaman Jaringan Komputer Berdasarkan Analisis Forensik Jaringan, Jurnal Ilmu Teknik Elektro Komputer Dan Informatika (Jiteki) Vol. 3, No. 1, Universitas Ahmad Dahlan Yogyakarta, Indonesia.

[2] Syarif Maulana, 2017, Pengujian dan Analisis Keamanan WPA2 dan Signal Strength pada Router Berbasis OpenWrt. Vol.2 No.3 2017: 105-111. Fakultas Teknik Universitas Syiah Kuala.

[3] Sony simaluntur, 2014. Analisis Keamanan Jaringan Wireless LAN (WLAN) Pada PT. PLN (Persero) Wilayah P2B Area Sorong, Jurnal Teknologi dan Rekayasa, Volume 19 No. 3, Universitas Gunadarma.

[4] Ilham Eka Putra. 2013, Perancangan Jaringan Hotspot Berbasis Mikrotik Router Os 3.3.0, Jurnal Teknoif, Vol.1, No.1, Edisi Apri. Stmik Indonesia Padang.

[5] Muhammad Muhammad, Ibrahim Hasan, At All. 2016), Analisa Dan Pengembangan Jaringan Wireless Berbasis Mikrotik Router Os V.5.20 Di Sekolah Dasar Negeri 24 Palu, Vol.2 No.1 Januari-Juni. Stmik Bina Mulia Palu.

[6] Guntoro, At All. 2020, Evaluasi Performance Jaringan Internet Kampus Menggunakan Quality Of Service (Qos). Prosiding-Seminar Nasional Teknologi Informasi \& Ilmu Komputer(Semaster) Vol 1.No.1 2020 Hal 280-290 E-Issn: 2774 1990. Universitas Lancang Kuning. 